\title{
Factores epidemiológicos en la prevalencia de mastitis subclínica en vacunos lecheros de pequeños productores de la irrigación "San Felipe"- Huaura
}

\author{
Epidemioñogical factors in the prevalence of subclinical al mastititis smallholder dairy cattle \\ production systems in the irrigation San Felipe - Huara
}

\author{
Paola Cordero $^{1}$; Ivonne Salazar²; Segundo Gamarra ${ }^{3}$
}

\begin{abstract}
Resumen
Mediante la prueba del California Mastitis Test (CMT), se evaluaron 1.080 cuartos pertenecientes a 270 vacas de raza Holstein $(94 \%)$ y criollos o cruzados (6 \%), entre vacas multíparas y de primer parto. La prevalencia encontrada para mastitis subclínica fue de $21,58 \%$. Se manejó un indicativo epidemiológico denominado Índice de Mastitis Subclínica (IMSC), el cual arrojó un índice de 0,84 encontrándose elevado si lo comparamos con 0,5 que es lo deseable para este tipo de ganadería; la relación bajo riesgo/alto riesgo (BR/AR) es de 7,35, lo que significa, que por cada cuarto de alto riesgo hay 7,35 cuartos de bajo riesgo; este valor siempre debe mantenerse elevado, hasta incluso mayor a 10 . Se realizó análisis microbiológicos a un total de 25 muestras de leche, provenientes de cuartos mamarios con grado 3 de mastitis subclínica, pertenecientes a 12 vacas en ordeño, de las cuales 14 muestras resultaron positivas al cultivo (56 \%) y 11 negativas (44\%). Los microorganismos encontrados fueron de tipo ambiental: Staphylococcus albus (43\%), Streptococcus no hemolítico (21\%), Escherichia coli (29\%) y Enterobacter aerogenes (7 \%). Para el análisis de las variables epidemiológicas se utilizó un modelo de regresión logística multivariado y se obtuvo el grado de asociación para la presentación de mastitis subclínica mediante los valores de Odds ratio (OR). Los factores de riesgo con mayor fuerza de asociación fueron: cama húmeda y muy húmeda, lo que se encuentra relacionado con la falta de higiene en los establos, convirtiéndolos en reservorios de patógenos ambientales.
\end{abstract}

Palabras clave: mastitis; prevalencia; factores de riesgo; odds ratio.

\begin{abstract}
Using The California Mastitis Test (CMT), 1080 mammary quarters from 270 cows, Holstein (94\%) and Creole or undetermined breed ( $6 \%$ ), and including multiparous and uniparous cows, were evaluated. The prevalence of subclinical mastitis was $21,58 \%$. The index of sub clinical mastitis (IMSC), an epidemiological indicator, was 0,84 , which was found to be high when compared to the ideal value of 0,5 for this type of farming; the relationship low risk / high risk was 7,35, which means that for each quarter at high risk there were 7, 35 quarters at low risk; this value should always be kept high, even higher than 10. Microbiological analyses were performed in 25 milk samples from mammary quarters with subclinical mastitis grade 3 from 12 milking cows. 14 samples (56\%) yielded positive culture and 11 (44\%) gave negative culture. All the microorganisms found were environmental: Staphylococcus albus (43\%), non-hemolytic Streptococcus (21\%), Escherichia coli (29\%), and Enterobacter aerogenes (7\%). A multivariate logistic regression model was used for the analysis of epidemiological variables to obtain the degree of association for the presentation of subclinical mastitis through the Odds ratio (OR) values. The risk factors with the strongest association were wet and very wet soil, which is related to the lack of hygiene in the stables, making them reservoirs of environmental pathogens.
\end{abstract}

Keywords: mastitis; prevalence; risk factors; odds ratio.

\section{Introducción}

El término mastitis es la inflamación de la glándula mamaria ocasionada por factores físicos, químicos, mecánicos o infecciosos, que se caracteriza por un incremento de las células somáticas en la leche y por alteraciones patológicas en el tejido mamario. Según el curso evolutivo de las mastitis, estas pueden presentarse clínicamente en forma hiperaguda, aguda, subaguda y crónica; sin embargo, el tipo más frecuente e importante es la forma subclínica (D’Pool, 2002). Esta última es una forma crónica de mastitis que ocurre sin cambios clínicos aparentes, en la mayor parte de los casos, aunque existen pequeñas lesiones activas responsables de algunos

\footnotetext{
1 Facultad de Zootecnia. Universidad Nacional Agraria La Molina, Lima (Perú). Email: malakatonche@hotmail.com

2 Facultad de Zootecnia. Universidad Nacional Agraria La Molina, Lima (Perú). Email: sri@lamolina.edu.pe

3 Facultad de Zootecnia. Universidad Nacional Agraria La Molina, Lima (Perú). Email: sggc@lamolina.edu.pe
} 
cambios en la leche, como disminución de la producción y del porcentaje de sólidos no grasos así como el aumento de células blancas (Ferreira de la Cuesta, 2003).

La mastitis bovina es considerada la enfermedad más importante que afronta la industria lechera a nivel mundial, en cuanto a pérdidas económicas se refiere, ya que tras sufrir una mastitis moderada o grave, la producción disminuye aproximadamente en un 20 \% (Schmidt, 1971; Blood y Radostits, 1992). Otro aspecto importante a ser considerado es que la leche contaminada con bacterias se convierte en un producto inapropiado para el consumo humano, ya que puede favorecer la diseminación de enfermedades zoonóticas. Además, la presencia de mastitis ocasiona dificultades en el procesamiento de la leche a la industria láctea (Blood y Radostits, 1992; Arauco, 2007).

Kleinschroth, Rabold y Deneke (1991) mencionan que la formación de una mastitis depende de diversos y numerosos factores (vaca, medio ambiente y germen causal). Por este motivo se la califica como "enfermedad multifactorial". El riesgo de infección está determinado por la relación del animal con el medio ambiente. Las influencias desfavorables del medio ambiente (errores en el ordeño, animales en malas condiciones de estabulación y alimentación, etc.) conducen a un debilitamiento de la capacidad defensiva de la ubre y favorecen la infección, de la misma forma que la favorecen la higiene insuficiente, las lesiones de la ubre y la proliferación de gérmenes alrededor del animal.

La prueba de California para Mastitis (CMT), por su simplicidad, rapidez, costo y aplicabilidad en el campo sigue siendo la más usada para el diagnóstico de la mastitis subclínica (Faría et al., 2005). En la cuenca lechera del sur del país (Arequipa, Moquegua y Tacna) la empresa Leche Gloria S.A., en el año 1976, encontró que la prevalencia de mastitis subclínica era de 26,57 $\%$. Salas, en 1982, reportó en el sector lechero de la Joya, un resultado de 29,62 \% y el índice de la prueba California Mastitis Test (ICMT) fue de 0,917; en Lima, Arana (1992) reporta una prevalencia de 64,96 \% y un ICMT de 1,90. Por su parte, Ramírez y Edinson (2002) presentan resultados de ICMT promedios en el establo Santa Juana (provincia de Huaura) para los periodos 1998,1999 y 2000 de: 1,62, 1,54 y 0,68, respectivamente. Asimismo, Romero (1997) en la zona de Puente Piedra, halló en promedio un ICMT de 1,50 y un valor de 3,908 de Relación Bajo Riesgo/Alto Riesgo.

Los agentes infecciosos que producen mastitis se dividen en contagiosos y ambientales. La mastitis contagiosa es causada por microorganismos como: Staphylococcus aureus, Streptococcus agalactiae, Corynebacterium bovis, Mycoplasma spp y sus reservorios son la glándula mamaria y la leche de vacas infectadas. La mastitis ambiental es producida por gérmenes Gram-negativos, habitantes normales del ambiente como, Escherichia coli, Klebsiella spp., Enterobacter spp., Serratia spp., Pseudomonas spp. y Proteus spp. y algunas bacterias Gram positivas como: Streptococcus uberis y Streptococcus dysgalactiae (Philpot y Nickerson, 2002).
El objetivo de este estudio fue determinar los factores epidemiológicos que influyen en la prevalencia de mastitis subclínica, calcular el Índice Sanitario de mastitis (ICMT), la relación Bajo riesgo/Alto riesgo (BR/AR) y aislar los patógenos asociados a la inflamación mamaria en vacas en lactación.

\section{Materiales y métodos}

De una población de 100 socios ganaderos de la Irrigación "San Felipe" se tomó al azar a 51 de ellos, este tamaño de muestra se determinó mediante asignación proporcional con un nivel de confianza de $95 \%$, representando adecuadamente a la población objetivo.

Se evaluaron 1.080 cuartos pertenecientes a 270 vacas, de las cuales 254 eran de raza Holstein y 16 criollas o cruzadas, entre multíparas y de primer parto, exceptuándose aquellas vacas recién paridas y próximas a seca; no se consideró etapa de lactación, edad, ni número de partos, por falta de registros de ganaderos. Las vacas pertenecían a los socios de la Asociación de Ganaderos de la Irrigación San Felipe, ubicada en el distrito de Végueta, provincia de Huaura, departamento de Lima, con una temperatura de $18{ }^{\circ} \mathrm{C}$, humedad relativa de $82 \%$ y una altitud de $04 \mathrm{msnm}$.

Las principales fuentes de alimentación del ganado son: panca, maíz chala y alimento concentrado elaborado en la Asociación. Las vacas son ordeñadas dos veces al día y sólo el $6 \%$ de ganaderos hacen uso del ordeño mecánico. Los animales se encuentran en corrales precarios: piso de arena, techo, comederos y bebederos rústicos; en algunos casos, se observan comederos y bebederos de cemento.

Se estudiaron 12 variables con el objetivo de determinar cuáles constituían factores de riesgo para la presentación de la mastitis subclínica, agrupándose en prácticas de manejo y medio ambiente: (a) Vacas alimentadas luego del ordeño, (b) No uso de productos para secar, (c) Forma de secado progresivo, (d) No se hace sellado post ordeño, (e) No se lava los pezones, (f) No se hace despunte, (g) No se seca los pezones, (h) Se seca con un mismo trapo, (i) Tipo de ordeño, (j) Cama seca, húmeda o muy húmeda (factor ambiental). Los datos se obtuvieron por observación directa del proceso de ordeño y a través de encuestas (12 preguntas) realizadas a los productores, haciéndose énfasis en el momento y condiciones en que se desarrolló el ordeño.

Se realizó la prueba de California Mastitis Test (Blowey y Edmondson, 1995) a todas las vacas en lactación para determinar la prevalencia de mastitis subclínica, el Índice de California Mastitis Test (ICMT) o Índice sanitario (IS) y la relación Bajo Riesgo/Alto Riesgo (BR/AR) siguiendo el protocolo según Mellenberger y Roht (2000) y Blowey y Edmondson (1995). La lectura de la prueba de California Mastitis Test (CMT) se calificó e interpretó según Mellenberger y Roth (2000).

Se realizó análisis microbiológico a un total de 25 muestras de leche proveniente de los cuartos mamarios de vacas con grado 3 a la prueba de CMT. Para la extracción de la muestra se utilizó la técnica de Kleinschroth et al. (1991) y Blowey y Edmondson (1995). Los medios de 
aislamiento fueron agar sangre, agar Mac conkey y agar manitol salado; la identificación se realizó con los medios TSI, citrato y LIA.

Para el análisis estadístico se utilizó el análisis de Regresión Logística, se halló la probabilidad de ocurrencia de la Mastitis Subclínica, a partir de la observación de una serie de variables independientes. La ecuación de la Regresión Logística es la siguiente:

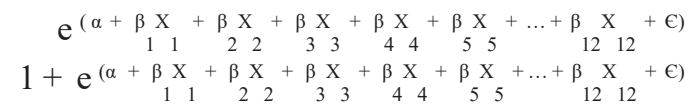

Donde:

$\Pi=$ Probabilidad de ocurrencia de mastitis subclínica.

$\beta_{(1-12)}=$ Coeficiente del modelo.

$\mathrm{X}_{(1-12)}=$ Variables epidemiológicas.

$\left.\mathrm{e}^{\left(\alpha+\beta_{1} \mathrm{X}_{1}+\ldots+\beta_{12} \mathrm{X}\right.}+\epsilon\right)=$ Exponente del modelo.

Las variables independientes son las siguientes:

$\mathrm{X}_{1}=$ Cama seca.

$\mathrm{X}_{2}=$ Cama húmeda.

$\mathrm{X}_{3}=$ Cama muy húmeda.

$\mathrm{X}_{4}=$ Vacas son alimentadas luego del ordeño.

$\mathrm{X}_{5}=$ No se usa productos para secar.

$\mathrm{X}_{6}=$ Forma de secado progresivo.

$\mathrm{X}_{7}=$ No hace sellado post ordeño.

$\mathrm{X}_{8}=$ No lava los pezones.

$\mathrm{X}_{9}=$ No hace despunte.

$\mathrm{X}_{10}=$ No seca los pezones.

$\mathrm{X}_{11}=$ Seca con un mismo trapo.

$\mathrm{X}_{12}=$ Tipo de ordeño.

Para el procesamiento de los datos se utilizó el tabulador electrónico Microsoft ${ }^{\circledR}$ Office, Excel 2003 y el paquete estadístico STATA versión 10.0 para Windows.

\section{Resultados y discusión}

Los resultados de la evaluación de 1.080 cuartos de 270 vacas en ordeño por medio de la Prueba de California Mastitis Test, se presentan en la Tabla 1. La prevalencia de mastitis subclínica fue de $21,58 \%$, valor superior a lo recomendado por Philpot y Nickerson (2002) quien considera aceptable un $12 \%$ de prevalencia en vacas en producción y a lo recomendado por Delgado (comunicación personal, 2009) para nuestras condiciones (menor o igual a $15 \%$ ). Es posible que esta mayor prevalencia de mastitis subclínica sea consecuencia de diversos factores, tales como la falta de higiene en el área de alojamiento de las vacas y la inadecuada rutina de ordeño. Arana (1992) en la ciudad de Lima, encontró una prevalencia de mastitis subclínica de $64,96 \%$, lo que significa que todas las vacas tienen al menos un cuarto infectado. Esta prevalencia es mayor a la encontrada en esta investigación, posiblemente por el ordeño mecánico utilizado, ya que en este hay mayor riesgo de infección por uso continuo de pezoneras, sumado al hacinamiento de vacas que favorece una mayor humedad y suciedad en los corrales.

El ICMT (índice de California Mastitis Test) fue de 0,84 y según Delgado (comunicación personal, 2009) los cuartos evaluados se encuentran con un grado de infección de Mastitis Subclínica bajo ya que es menor a 1; sin embargo, Arauco (2007) indica que es deseable un valor menor a 0,5. El ICMT encontrado pudo estar relacionado, en primer lugar, al mayor número de Trazas (251) que se calificó, porque cierta cantidad de estas han podido ser negativas y no participar en la fórmula, y por lo tanto, disminuir el ICMT. En segundo lugar, también pudo estar afectado por los pezones considerados no funcionales (ciegos y casos de mastitis clínica) ya que alrededor del $2 \%$ de pezones totales fueron descartados, aumentando ligeramente el índice. El ICMT determinado en este trabajo está por debajo de lo reportado por Arana (1992) quien encontró un ICMT de 1,90, este ICMT elevado está relacionado con el alto número de cuartos con reacción positiva a la prueba de CMT.

La relación Bajo Riesgo/Alto Riesgo es de 7,35, deduciéndose que por cada cuarto de alto riesgo hay 7,35 cuartos de bajo riesgo; esta relación es baja porque en ordeño manual, como en este caso, se espera que sea 10 o incluso mayor a 10, ya que este tipo de ordeño en establos de baja producción de leche es más eficiente, pues en teoría, hay menor riesgo de mastitis que en el ordeño mecánico donde hay más posibilidades de infecciones por el uso continuo de pezoneras (Delgado, comunicación personal, 2009).

Tabla 1. Número de cuartos afectados con mastitis subclínica

\begin{tabular}{lllllll}
\hline Grado de infección & AI & PI & AD & PD & TOTAL & \% \\
\hline NEGATIVO & 118 & 156 & 132 & 168 & 574 & 54,56 \\
TRAZAS & 80 & 60 & 70 & 41 & 251 & 23,86 \\
GRADO $\mathbf{1}^{\mathbf{1}}$ & 32 & 19 & 28 & 22 & 101 & 9,61 \\
GRADO 2 $^{\mathbf{1}}$ & 20 & 18 & 17 & 23 & 78 & 7,41 \\
GRADO 3 $^{1}$ & 10 & 14 & 15 & 9 & 48 & 4,56 \\
Mastitis Clínica $^{2}$ & 7 & 3 & 5 & 5 & 20 & -- \\
Cuartos ciegos $^{2}$ & 3 & --- & 3 & 2 & 8 & -- \\
Cuartos totales & & & & & $\mathbf{1 0 8 0}$ & $\mathbf{1 0 0}$ \\
\hline
\end{tabular}

${ }^{1}$ Prevalencia de mastitis subclínica: (227 cuartos con G1, G2 y G3)/1052 cuartos totales) x $100=21,58 \%$. ${ }^{2}$ Cuartos descartados para determinar la prevalencia. 
La relación Bajo Riesgo/Alto Riesgo encontrada en este estudio es menor a la encontrada por Romero (1997) que fue de 3,91 y Arana (1992) que tuvo como resultado 2,51, en poblaciones de 80 y 39 vacas Holstein, respectivamente; lo que demuestra que los animales de estos establos tienen mayor probabilidad de presentar mastitis clínica, a pesar de tener poca población y mayor experiencia en producción lechera que la investigada.

Entre los factores epidemiológicos más resaltantes (Tabla 2 ) encontrados en las encuestas de campo, se obtuvo que el $84 \%$ de socios lavan los pezones antes de ordeñar, lo que favorece que la leche durante el ordeño, no se contamine con materia fecal. De los 43 socios que lavan los pezones antes del ordeño, solo 13 los secan, esta práctica en la rutina de ordeño es perjudicial ya que el hecho de lavar los pezones pero no secarlos antes del ordeño, favorece que se depositen bacterias en suspensión en el extremo de los pezones, lo que ocasiona que se incremente el riesgo de mastitis ambiental y aumente la contaminación bacteriana en la leche y, por lo tanto, no se garantiza una excelente calidad de la misma (Buxadé, 2002).

Tabla 2. Factores epidemiológicos registrados según encuesta de campo

\begin{tabular}{lccc}
\hline \multicolumn{1}{c}{ Variables } & $\mathrm{N}^{\mathrm{o}}$ & $\%$ & $\mathrm{~S}^{1}$ \\
\hline Vacas alimentadas luego del ordeño & 36 & 71 & $\mathrm{~ns}^{2}$ \\
Cama seca & 17 & 33 & $\mathrm{~ns}$ \\
Cama húmeda y muy húmeda & 34 & 67 & $\mathrm{~ns}$ \\
Usa productos para secar & 41 & 80 & $\mathrm{~ns}$ \\
Forma de secado progresivo & 23 & 45 & $\mathrm{~ns}$ \\
Forma de secado de golpe & 28 & 55 & -- \\
Lavado de pezones & 43 & 84 & $\mathrm{~ns}$ \\
Secado de pezones & 13 & 30 & $\mathrm{~ns}$ \\
Seca con un mismo trapo & 9 & 69 & $\mathrm{~ns}$ \\
Seca con papel & 4 & 31 & -- \\
Realiza despunte & 23 & 45 & $\mathrm{~ns}$ \\
Sellado post ordeño & 13 & 25 & $\mathrm{~ns}$ \\
Ordeño manual & 48 & 94 & $\mathrm{~ns}$ \\
Ordeño mecánico & 3 & 6 & $\mathrm{~ns}$ \\
Hizo por lo menos una vez CMT & 24 & 47 & -- \\
\hline
\end{tabular}

${ }^{1}$ Significancia según la regresión logística.

${ }^{2}$ No significativa $(\mathrm{p}<0,05)$.

De los 13 socios que secan los pezones, sólo cuatro secan con papel y el resto lo hace con un mismo trapo para todas las vacas en producción, favoreciendo así la proliferación de la infección de mastitis contagiosa ya que los medios de transmisión más relevantes son los utensilios de ordeño, las manos del ordeñador y el uso de toallas o trapos para secar varias vacas (Wattiaux, 2001).

El $55 \%$ de los socios no descarta los primeros chorros de leche previos al ordeño, favoreciendo la no detección y tratamiento a tiempo de las vacas con mastitis; asimismo, disminuye la estimulación táctil para que el ordeño sea rápido y se favorezca la secreción de oxitocina (Ruegg, 2002).
Después del ordeño, el $75 \%$ de los socios no hace uso de selladores, acrecentando el riesgo de infecciones causadas por microorganismos para mastitis contagiosa. El $67 \%$ de los socios tiene cama húmeda y muy húmeda lo que favorece que los pezones se ensucien y se contaminen con el estiércol, y aunque estos socios apliquen selladores, el poder germicida de estos se pierde porque su principal acción es contra microorganismos contagiosos, no contra infecciones ambientales, dado que su período de acción (1-2 horas) es relativamente corto (Buxadé, 2002).

El $71 \%$ de los ganaderos mantienen a sus vacas sin echarse por lo menos media hora después del ordeño; en este tiempo, el orificio del extremo del pezón ya se cerró, el esfínter recuperó su tono habitual y, por consiguiente, hay menor riesgo de entrada de gérmenes y con mayor razón cuando no se usa selladores.

El $47 \%$ de los socios ganaderos realizan la Prueba de California Mastitis Test por lo menos una vez, es decir, que en la Asociación de Ganaderos San Felipe, el $53 \%$ no realiza la prueba mensualmente, como se recomienda, favoreciendo que se desconozca la presencia de la mastitis en el hato, lo que trae como consecuencia que los socios desconozcan la causa de reducción de los componentes útiles de la leche y el aumento del nivel de elementos indeseables, traduciéndose en un producto menos aceptable y de menor valor (Blowey y Edmondson, 1995); asimismo, disminuye la producción de leche hasta en un $70 \%$ y aumentan los gastos de medicamentos y servicios veterinarios, entre otros (Buxadé, 2002). La mayoría de los ganaderos no realiza la prueba porque piensa que el costo es elevado o porque toma demasiado tiempo, pero también por desconocimiento de las pérdidas en la producción y económicas que produce la mastitis subclínica.

Las 12 variables evaluadas según la regresión logística resultaron no significativas $(p<0,05)$, es decir, estadísticamente no constituyen factores de riesgo potenciales de mastitis en la Asociación de Ganaderos de la Irrigación "San Felipe", sin embargo, las variables "cama húmeda y/o muy húmeda" según su OR (Odds ratio) pueden considerarse como factores de riesgo en esta investigación ya que presentaron respectivamente $1,03 \mathrm{y}$ 1,06 veces más posibilidades de que las vacas evaluadas presenten mastitis cuando la cama se encuentra en estas condiciones. El exceso de humedad en los corrales, se pudo deber a que algunas instalaciones, improvisadas para que el ganado tome agua, estaban mal construidas o muy precarias ya que permitían que el agua se derramara o encharcara dentro del corral, observándose incluso que ciertas vacas se hundían y resbalaban en la cama; además, la falta de extracción de las heces del corral producía una excesiva acumulación de materia fecal y, por ende, más contaminación de los pezones de la vaca.

Las variables estudiadas, estadísticamente, no constituyeron factores de riesgo, pero desde el punto de vista biológico y según la revisión bibliográfica realizada, muchas de ellas sí constituyen factores de riesgo en la presentación de mastitis subclínica.

Los análisis microbiológicos realizados a 25 cuartos 
mamarios con Grado 3 de mastitis subclínica, pertenecientes a 12 vacas en ordeño, dieron los siguientes resultados: $14(56 \%)$ muestras resultaron positivas al cultivo y 11 (44\%) negativas. Los microorganismos encontrados fueron en su totalidad del tipo ambiental: Staphylococcus albus (43\%), Streptococcus no hemolítico (21\%), Escherichia coli (29\%) y Enterobacter aerogenes (7\%). Es posible que la presencia de estos patógenos sea debido a la falta de higiene en los establos, la abundante acumulación de estiércol seco y húmedo convirtiéndolos en reservorios, que al estar en contacto con los pezones de las vacas recién ordeñadas propician la oportunidad de infección (Azócar, 2001; Philpot y Nickerson, 2002 y Schreiner y Ruegg, 2003).

\section{Literatura citada}

La prevalencia de mastitis subclínica encontrada mediante la Prueba de California Mastitis Test fue de 21,02 por ciento, valor por encima de lo considerado normal para las condiciones del estudio (15\%). Estadísticamente, las 12 variables epidemiológicas evaluadas $(p<0,05)$, no constituyen factores de riesgo en la presentación de mastitis, al ser no significativas. El índice sanitario de mastitis $(0,84)$ demuestra que el hato se encuentra en un grado infección de mastitis subclínica baja. La relación bajo riesgo/alto riesgo $(7,35)$ es menor, porque se espera que sea mayor a 10 en establos con predominancia de ordeño manual, como en este caso. Los microorganismos aislados fueron: Staphylococcus albus (43 \%), Streptococcus no hemolítico (21\%), Escherichia coli (29 $\%$ ) y Enterobacter aerogenes (7\%), en su totalidad son microorganismos de tipo ambiental.

\section{Literatura citada}

Arana, R. 1992. Prevalencia de mastitis subclínica en el establo de la Facultad de Medicina veterinaria de la Universidad Mayor de San Marcos. Tesis Médico veterinario. Universidad Nacional Mayor de San Marcos. Lima, Perú.

Arauco, V.2007. Monitoreo epidemiológico de la Mastitis Subclínica. Disponible en: http://www.engormix.com/s articles_view.asp?art=1768.

Azócar, S. 2001. Prevalencia, incidencia y etiología de mastitis en un centro de acopio lechero, comuna de María Pinto, región metropolitana. Tesis (título de médico veterinario). Universidad de Chile. Disponible en: http://www.cybertesis.cl/tesis/uchile/2001/azocar_j/ html/index-frames.html.

Blood, D. y Radostits, D. 1992. Medicina veterinaria. Vol I. Interamericana Mc Graw - Hill, pp. 539-602.

Blowey, R. y Edmondson, P. 1995. Control de la mastitis en granjas de vacuno de leche (Guía ilustrada y práctica). Zaragoza, España: Editorial Acribia S.A.

Buxadé, C. 2002. El ordeño en el ganado vacuno: aspectos claves. DF, México: Ediciones Mundi - Prensa.

Faria, J.; Garcia, D.; Pool, G.; Valero, K.; Allara, M. y Angelosante, G. 2005. Detección de mastitis subclínica en bovinos mestizos doble propósito ordeñados en forma manual o mecánica. Comparación de tres pruebas diagnósticas. Maracaibo, Venezuela. 15(2): 1 - 14. Ferreira de la Cuesta, G. 2003. Patología veterinaria. Editorial Universidad de Antioquia, pp. 522-526.

Kleinschroth, E.; Rabold, Karl. y Deneke, Jürgen. (1991). La mastitis. Diagnóstico, prevención y tratamiento. España: Ediciones médicas.

Mellenberger, R. y Roth, C. 2000. Hoja de información de la Prueba de Mastitis California (CMT). Disponible en: http://www.uwex.edu/MilkQuality/PDF/CMT\%20 spanish.pdf.

Philpot, W. y Nickerson, S. 2002. Ganando la lucha contra la mastitis. Naperville, IL, USA: Wesfalia Surge.

Romero, C. 1997. Comparación de los métodos de California Mastitis Test y White Side Modificado para la determinación de índices de detección de mastitis subclínica en el ganado vacuno. Tesis (Ingeniero Zootecnista). Universidad Nacional del Centro del Perú. Huancayo, Perú.

Ruegg, P. 2002. Control de la Mastitis. Novedades lácteas. Instituto Babcock - Universidad de Wisconsin. 405, 1 - 14. Disponible en: http://www.uwex.edu/ces/ pubs/.

Schmidt, G. 1971. Biología de la lactación. Zaragoza, España: Editorial Acribia.

Wattiaux, M. 2001. Mastitis: prevención y detección. Instituto Babcock para la investigación y desarrollo internacional de la Industria Lechera. 